$1-2006$

\title{
A Strategic Interpretation of Legal Transplants
}

Nuno Garoupa

ngaroup@gmu.edu

Anthony Ogus

Follow this and additional works at: https://scholarship.law.tamu.edu/facscholar

Part of the Law Commons

\section{Recommended Citation}

Nuno Garoupa \& Anthony Ogus, A Strategic Interpretation of Legal Transplants, 35 J. Legal Stud. 339 (2006).

Available at: https://scholarship.law.tamu.edu/facscholar/424

This Article is brought to you for free and open access by Texas A\&M Law Scholarship. It has been accepted for inclusion in Faculty Scholarship by an authorized administrator of Texas A\&M Law Scholarship. For more information, please contact aretteen@law.tamu.edu. 


\title{
A Strategic Interpretation of Legal Transplants
}

\author{
Nuno Garoupa and Anthony Ogus
}

\begin{abstract}
In this paper we provide a strategic explanation for the spontaneous convergence of legal rules that nevertheless, in many instances, falls short of unification across jurisdictions. We identify a free-riding problem and discuss its implications for legal integration. We argue that countries hesitate to adapt their laws to those of another jurisdiction because they hope to free ride on efforts toward convergence. Unification (by transplant) and harmonization (by convention) of legal rules emerge as obvious corrective interventions to a coordination failure, thus solving the free-riding problem. However, unification and harmonization could also be serious policy mistakes either because convergence is absent owing to very high costs of importing and adjustment or owing to agency costs.
\end{abstract}

\section{INTRODUCTION}

The extent to which one legal system may adapt its own principles and procedures to those of foreign jurisdictions has been the subject of an interesting recent literature (notably, Legrand 1996, 1999; Hesselink 2001). The issue is important in an age when considerable efforts are

NUNO GAROUPa is Professor of Law and Economics at the Universidade Nova de Lisboa. ANTHONY OGUS is Professor of Law at the University of Manchester School of Law. We thank Benito Arruñada, Ségoléne Barbou des Places, Antonio Cabrales, Patricia Funk, João Gata, Fernando Gómez-Pomar, Peter Grajzl, Canice Prendergast, and Dieter Schmidtchen as well as seminar participants at the University of Aveiro, University of Hamburg, University of Minho, Universidade Nova de Lisboa, Universitat Pompeu Fabra, and at the 2003 annual meeting of the European Association of Law and Economics for useful comments. We are extremely grateful to the editors, Eric Posner and Alan Sykes, and an anonymous referee for suggestions that have much improved the paper. Nuno Garoupa acknowledges financial support from Fundação Calouste Gulbenkian (Gulbenkian Foundation), from Bolsas Nova Forum, and from Fundação do Ministério de Ciência e Tecnologia (Portuguese Ministry of Higher Education and Science), POCTI/JUR/55752/2004. The usual disclaimers apply. 
being made to integrate legal systems, particularly within the European Union. But it is part of a bigger set of questions concerned with how legal systems evolve in relation to one another. Jurists have not been slow to develop theories on such evolution (for example, Watson 1985; Zimmermann 2001) but have largely ignored economic explanations.

In a recent important paper, Berkowitz, Pistor, and Richard (2003) argued that the ability to successfully adapt transplanted law to local conditions has a major effect on economic development. Also, in recent years, the field of comparative economics and institutional analysis has experienced a renewed interest that focuses on efficiency of legal systems, consequences of transplantation, and the politics of institutional design (see Djankov et al. 2003a, 2003b).

A major step forward was taken with the hypothesis that competition between the suppliers of legal rules will significantly influence the evolution of law (see, especially, Mattei and Pulitini 1991; Mattei 1994; Ogus $1999,2002 a){ }^{1}$ If domestic industries competing in international markets find that their national legal system imposes on them higher costs than those incurred by their foreign competitors operating under a different jurisdiction, they will apply pressure on their lawmakers to reduce the costs. That demand will be strengthened by the threat of migration to the more favorable jurisdiction, assuming that there are.no barriers to the freedom of establishment and to the movement of capital. Also, to the extent that this is allowed by the private international law of their home jurisdiction, firms may be able to select the jurisdiction whose principles are to apply to their transactions or business. As regards supply, lawmakers are likely to respond positively to the demand from domestic industries because pressure by the latter can have a decisive influence on politicians' behavior. Lawmakers will also be motivated, particularly in small countries heavily dependent on international trade, to attract firms from other jurisdictions and multinational corporations since that should entail increased investment, demand for labor, and tax revenue.

In the United States, there has been a long debate over the merits and demerits of competitive regulatory federalism by emphasizing the pressure for legal change from trade of goods and services and mobility of physical or human capital versus undesirable social outcomes (for example, Levmore 1983; Sykes 2000). In corporate law, for example,

1. For a more general discussion of competition between jurisdictions within the United States and the European Union, see Esty and Geradin (2001). 
the discipline introduced by market forces enhances presumptive benefits from competition, although under some conditions competitive federalism may fail to produce the socially optimal outcome (Romano 1987, 2002, 2005; Bebchuk 1992; Bebchuk and Hamdani 2002; Kahan and Kamar 2002; Bebchuk and Cohen 2003; Roe 2003). Similarly, in environmental law, where the costs imposed by regulating industrial pollution could generate adequate interstate competition, there may nevertheless exist constraints that introduce resistance to the most efficient outcome (Revesz 1992, 1996, 2000). Other areas of law, such as corporate fraud or product liability, have been discussed to similar effect (for product liability, see Hay 1992; for corporate fraud, see Ribstein 2002; in a broader constitutional context, see Posner 1987). Generally speaking, the law and economics literature is not positive concerning the merits of unification of law in the United States and harmonization of law in Europe (for the United States, see Ribstein and Kobayashi 1996a, 1996b; for the European Union, see Easterbrook 1994; Mattei 1998; Esty and Geradin 2000; Linarelli 2003; Faure 2003).

In an earlier paper (Ogus 1999), one of us investigated the implications of the analysis for the acceptance of transplants (meaning unilateral adoption of legal norms from other jurisdictions) and convergence between legal systems. It is envisaged that such a development is likely to occur in relation to homogenous legal products, those areas of law in which there is unlikely to be a significant variation in preferences between market actors in different jurisdictions. The best examples are to be found in facilitative law, which provides mechanisms for ensuring mutually desired outcomes (contracts, corporations, other forms of legal organizations, and dealings with property). The assumed preference is for the minimization of legal costs. In contrast, there is no expectation that competition between national systems will lead to a convergence of heterogeneous legal products that can be mainly identified with interventionist law (tort and regulatory law, but also those aspects of contract, property, and corporate law that confer protection on parties assumed to be disadvantaged by processes of free bargaining, for example, consumers, employees, tenants, and [in some contexts] shareholders). Here preferences may vary between countries as to the different combinations of the levels of legal intervention and to the price that must be paid for them. If this is the case, there is no necessary expectation that competition between national legal systems will lead to convergence, 
since much will depend on national preferences regarding the level of protection. $^{2}$

Nor is it to be assumed, in relation to homogenous products, that competition will always prevail. There are key players in the processes of legal change who may find it in their interests to oppose competition. Professional lawyers are the most prominent in this category; inside or outside government, they can exert a huge influence on outcomes, in particular by their evaluation of what is legally feasible. Some lawyers may benefit from the increased demand for their services following migration to their jurisdiction or adoption of it under a choice-of-law clause. That would suggest a strategy of supporting cost-reducing law reform as a response to the pressure of competition from other legal systems. On the other hand, it is perhaps equally likely that the majority of lawyers would benefit from resisting the competitive processes, maintaining their control over the supply of domestic legal skills, and deriving increased income from unreformed and more costly legal principles (see Hadfield 2000; Ogus 2002a; but see Ribstein 2004).

In this paper, we provide a model of interactions between jurisdictions based on the balance between, on the one hand, the pressure for convergence generated by transboundary trade of goods and services, including capital, and, on the other, the costs of adjustment (including rent seeking). Our first step is to illustrate the idea of legal transplants as an equilibrium outcome of a game played by a continuum of jurisdictions. If there is transboundary interaction between different sets of legal rules and practices, there are several possible equilibria. Convergence (in the sense of adoption of, or adjustment to, norms from other sets of legal rules and practices) of legal rules is likely if importing and adjustment costs are low and symmetric and unlikely if such costs are high and asymmetric. Transplants are likely if importing and adjustment costs are asymmetric and low for the influenced country. A first simple model is developed in Section 2.

Nations, more specifically national legislatures, are the focus of attention in our model. Nevertheless, we recognize the impact of individual decision making on legal developments. We explicitly discuss the role of private intermediaries who, through their choice of legal system,'can influence the convergence of legal regimes and practices, thereby reducing the need for public intervention. Also, we note that public harmo-

2. The situation may be different in the face of transboundary externalities. See Esty and Geradin (2001). 
nization of legal regimes and practices restricts the choices available to individuals when involved in transboundary transactions.

The concepts of convergence, harmonization, and unification seem to be imprecise notions in comparative law (see Smits 1998). Convergence is used to refer to the coming together of legal systems, concepts, principles, or norms. Harmonization is seen as an approximation of national or state laws by virtue of provisions laid down by law, regulation, or administrative action. Unification is an extreme version of harmonization in which differentiability or flexibility is ruled out and no derogation in the preempted areas is allowed. ${ }^{3}$ Implications for harmonization and unification from our model are considered in Section 3.

In Section 4, we discuss the implications of a free-riding problem that makes it impossible for a unique legal culture to emerge. Unification and harmonization of legal rules by a "supergovernment" or a central authority in a legal federation could be the response to a market or coordination failure. However, unification and harmonization could also be serious policy mistakes, depending on the parameters of the present model, either because import and adjustment costs are simply too high or because of duplication of costs. These two observations generate different predictions and legal policy implications with respect to unification of law in the United States and harmonization of law in Europe as well as legal development in former colonies. These implications are discussed in Section 4, and we conclude with some final remarks in Section 5 .

\section{A FIRST SIMPLE MODEL}

Suppose that there is a large number of countries or jurisdictions, each with a different initial set of legal rules and practices. Jurisdictions are randomly matched in interactions within their productive activities in goods and services, including capital flows. For any given match, these transboundary activities are affected by the legal rules and practices of both jurisdictions. Each jurisdiction has some willingness to adapt to its partner's legal rules and practices by changing its own legal order. The strategies available to players in this game are $\{\mathrm{W}, \mathrm{N}\}$, where $\mathrm{W}$ stands for willingness and $\mathrm{N}$ for no willingness to change legal order.

Our definition of willingness to change is somehow related to trans-

3. Our understanding is similar to van Gerven (2004). 
planting. However, transplants are usually perceived as unilateral changes of a legal order by which one jurisdiction imports legal norms from another jurisdiction. The transplant effect consists of developing a given legal order by (partially or fully) importing and adopting foreign law and legal practices (taking the view and the taxonomy in Berkowitz, Pistor, and Richard 2003). In our model, we allow for the possibility that both jurisdictions adjust their legal systems. In fact, willingness to change in this model means being receptive to accommodating rules and practices from another jurisdiction or having a flexible position concerning especially facilitative legal rules and practices. Thus, we prefer to use willingness to change as a more general way of looking at transplants. No transplanting is of course a consequence of no willingness to change, since it indicates development of a given legal order internally with no influence or concern for outside law and legal practices.

When we say in our model that both jurisdictions are willing to adjust legal rules, it does not mean that both will adopt exactly the same rules or that the emergent law will be the same for both. What we have in mind is that both countries are willing to exert some effort to accommodate or make concessions to foreign jurisdictions and that this effort is costly. ${ }^{4}$

Ours is also a model of public willingness to change the law in the sense that the players are the countries or jurisdictions; that is, each player can be described as a benevolent legislator or the median voter in each relevant jurisdiction. The adjustment of the law and legal practices is decided by the country, being that legislator or median voter. Hence, we do not explicitly consider the influence of private parties on achieving such adjustment through the courts (as in the case of business and corporate law) or through law firms (as in the case of contracts). However, the private interest in having the law changed will be taken into consideration below when we define the costs of adjustment (on private willingness to change the law, see Ribstein 1993).

For each matching, there are four possible situations:

1. Both jurisdictions are willing to adjust, and both legal rules and practices converge. We designate this outcome as a convention effect

4. Therefore, we do not determine the exact nature of the legal culture or structure of the law in equilibrium. Also, we do not conceive the willingness to adjust as an absorber decision node after which no further adjustments can be made. 
since it could be seen as both parties agreeing on some common legal ground.

2. Jurisdiction $A$ is willing to adjust (import legal rules), but jurisdiction $B$ is not willing to adjust. This outcome can be seen as a transplant effect.

3. Jurisdiction B is willing to adjust (import legal rules), but jurisdiction $\mathrm{A}$ is not willing to adjust. Again, we have a transplant effect, but in the opposite direction.

4. Both jurisdictions are unwilling to adjust their legal orders.

When both partners are willing to adjust legal rules and practices, the payoff of each player is $1-\sigma_{i} L$, where 1 is the (normalized) expected gain from being able to successfully interact with other countries and $\sigma_{i} L$ is the total cost of adjusting to other legal rules and practices, with $i=\mathrm{A}, \mathrm{B}$. The higher $L$ is, the higher the total cost relative to the payoff from being able to successfully interact with other countries; the higher $\sigma_{i}$ is, the higher the cost of adjusting to other legal rules and practices for country $i$. In a symmetric game without duplication of costs in the technology of adjustment, we would expect $\sigma_{i}=\frac{1}{2}$ for both $i=\mathrm{A}, \mathrm{B}$. With duplication of costs in the technology of adjustment, we would have $\sigma_{\mathrm{A}}=\sigma_{\mathrm{B}}>\frac{1}{2}$, which means that there is some waste when both jurisdictions adjust their legal frameworks. Conversely, with reduction of costs in the technology of adjustment, we would have $\sigma_{\mathrm{A}}=\sigma_{\mathrm{B}}<\frac{1}{2}$, which means that there are some savings. Finally, in an asymmetric game, we can have $\sigma_{\mathrm{A}} \neq \sigma_{\mathrm{B}}$.

For each jurisdiction, the total cost of adjusting includes (1) the direct costs of acquiring information, importing (for example, drafting a new law) and learning foreign legal rules and practices, and interpreting and applying them; (2) the rent-seeking or entrenchment costs of those who plausibly lose from changing legal rules (long-entrenched interests) and are willing to waste resources to avoid those changes (for example, lawyers or the bar association), with particular reference to litigation costs; (3) indirect costs due to the potential loss of legal coherence or consistency and potential contradictions and instability within the emergent law, given that some areas of the law will be more changed than others (that is, the complementarities of the law across different areas); ${ }^{5}$ (4) private legal-order costs that result from limiting the individual ben-

5 . This problem has been highlighted in an important branch of the comparative law literature. See Legrand (1996, 1999) and Teubner (1998). 
Table 1. Game Matrix

\begin{tabular}{ccc}
\hline & $\mathrm{W}$ & $\mathrm{N}$ \\
\hline $\mathrm{W}$ & Convention & Transplant \\
& $1-\sigma_{\mathrm{A}} L, 1-\sigma_{\mathrm{B}} L$ & $1-r_{\mathrm{A}} L, 1$ \\
$\mathrm{~N}$ & Transplant & No effect \\
& $1,1-r_{\mathrm{B}} L$ & 0,0 \\
\hline
\end{tabular}

efits from opting out of the current legal order or developing third-party arrangements, that is, by imposing public adjustment of the law, which is an imperfect substitute for private adjustment (assuming that existing arrangements allow for such adjustment); and (5) costs arising from lack of innovation since systems without local variations are less likely to innovate and adjust to dynamic preferences (for a more exhaustive listing of costs, see Ribstein and Kobayashi 1996a). We should also consider that if the law is adjusted by private influence (for example, a choiceof-law provision from a certain state to govern sovereign bond covenants), by the action of courts (for example, case law by the European Court of Justice or jurisprudence by the U.S. Supreme Court), or by the legal practice of multinational law firms (for example, by choosing a jurisdiction as the seat of the corporation or by a choice-of-law clause in a contract), the benefit from public adjustment of the law is lower, and therefore we should say that the relative cost is higher.

If only one partner is willing to adjust the legal rules of its jurisdiction (that is, only one partner is willing to exert some effort to accommodate or make concessions), both players get 1 , but only the partner introducing changes in their legal order bears the cost $r_{i} L$ with $i=\mathrm{A}, \mathrm{B}$. Naturally, we assume that $r_{i} \geq \sigma_{i}$ for all $i=\mathrm{A}, \mathrm{B}$; that is, the costs of adjustment are higher for a given country when the change is unilateral. Finally, if neither is willing to adjust its legal rules, then both players get zero since interaction is less successful. Table 1 summarizes the payoffs of the game.

In a symmetric game we would have $\sigma_{\mathrm{A}}=\sigma_{\mathrm{B}}$ and $r_{\mathrm{A}}=r_{\mathrm{B}}$, where each player has the same set of payoffs. However, in reality some countries have more influence or more ability to impose their own legal rules and practices and thus are more protected from the influence of foreign jurisdictions. The countries that are less prone to be influenced are called origins, and the remaining are called transplants. Which countries are 
origins is a matter of empirical controversy. ${ }^{6}$ In our model, origins are characterized by higher $\sigma$ and $r$ owing to the ability to exercise power over the other jurisdiction, which in turn will have a lower $\sigma$ and $r$. Origins have an advantage in the sense that their partners face a lower cost of switching, not only because origins are more powerful but also because many more countries will imitate them, hence creating a network effect (on legal culture as a network, see Ogus 2002a). Although the effect is not modeled here, it is taken into account in our postulate that transplants have lower switching costs. Origins are often considered as giving rise to legal families (for example, common law and civil law; see Zweigert and Kötz [1998] on origins and legal families), and adaptation within families is cheaper than between different families.

In summary, we consider that different legal regimes and practices may be more or less costly to adopt, depending on their influence. This is measured by higher switching costs for the more influential country and lower switching costs for the less influential country. Similarly, a regime that is well known and used may be cheaper to switch to than a brand-new regime (regardless of whether or not the countries are origins or transplants).

In Table 1 , notice the coordination problem of adjusting legal rules and practices. Country A would prefer its own set of legal rules and practices to prevail, while country $B$ would prefer its own set of legal rules and practices to prevail. The reason for that is that adjusting is costly. However, if no adjustment takes place, no productive interaction occurs, and both have a zero payoff. As a consequence, the equilibria of the game result in different legal cultures prevailing in the long run.

The solution to the game depends on the total costs being more or less than the expected gain normalized to one. In other words, the characterization of legal culture depends on the cost of importing and adjusting to different sets of legal rules and practices relative to its benefit.

Case 1. Suppose that $\min \left\{r_{\mathrm{A}}, r_{\mathrm{B}}\right\} L>1$ (import and adjustment costs are relatively high for both countries). There is a unique Nash equilibrium given by no effect. Since adjustment costs are very high, both countries choose not to import and adjust to the other's legal rules and practices.

Case 2. Consider now the case in which $\min \left\{r_{\mathrm{A}}, r_{\mathrm{B}}\right\} L<1<\max \left\{r_{\mathrm{A}}\right.$,

6. England, France, and Germany are uncontroversial origins. There is some controversy concerning Austria, Denmark, Finland, Norway, Sweden, Switzerland, and the United States and a very serious dispute with respect to Portugal and Spain. See Berkowitz, Pistor, and Richard (2003). 
$\left.r_{\mathrm{B}}\right\} L$ (important and adjustment costs are relatively high for one country-the origin-and relatively low for the other country-the transplant). There is a unique Nash equilibrium given by transplant in which the country with lower costs adjusts to the country with higher coststhe origin.

Case 3. The last possible case is one in which $\max \left\{r_{\mathrm{A}}, r_{\mathrm{B}}\right\} L<1$ (import and adjustment costs are relatively low for both countries). There are two Nash equilibria given by transplant $\langle\mathrm{W}, \mathrm{N}\rangle$ and $\langle\mathrm{N}, \mathrm{W}\rangle$ in pure strategies. There is also a mixed strategy equilibrium in which country A plays $\mathrm{W}$ with probability $x$ and plays $\mathrm{N}$ with probability $1-x$, and country $B$ plays $W$ with probability $y$ and plays $\mathrm{N}$ with probability $1-y$. The probabilities $x$ and $y$ are given by $\left(1-r_{\mathrm{B}} L\right) /\left[1-\left(r_{\mathrm{B}}-\sigma_{\mathrm{B}}\right) L\right]$ and $\left(1-r_{\mathrm{A}} L\right) /\left[1-\left(r_{\mathrm{A}}-\sigma_{\mathrm{A}}\right) L\right]$, respectively. This type of game in known in game theory as Hawk/Dove or Chicken.

By making use of mixed strategies in population games, we can say that a proportion $x$ of type A players will choose $\mathrm{W}$ and $1-x$ of type A players will choose $\mathrm{N}$; also a proportion $y$ of type $\mathrm{B}$ players will choose $\mathrm{W}$ and $1-y$ of type $\mathrm{B}$ players will choose $N$. As a consequence, the expected payoff of each player is given by $x$ for country B and $y$ for country A, thus decreasing in $L$. We call this outcome convergence since it is possible that some approximation between both countries takes place, the degree of actual convergence being higher when adjustment costs are lower.

In Figure 1, we represent the possible equilibria of the game in relation to different values of the relevant parameters. An important remark is that transplant (in the sense of unilateral switch) as the equilibrium of the game can occur only in asymmetric games in which one country has a much higher cost of adjustment; in symmetric games, there is no transplant, as only convergence is possible.

\section{IMPLICATIONS FOR LEGAL HARMONIZATION AND UNIFICATION}

Suppose now that a central or federal authority or a supergovernment exists and could unify or harmonize law by imposing legal rules and practices, which corresponds to enforcing the Pareto-dominant solution on all players. The immediate consequence is that this approach solves a potential market failure by which both players are unable to coordinate 


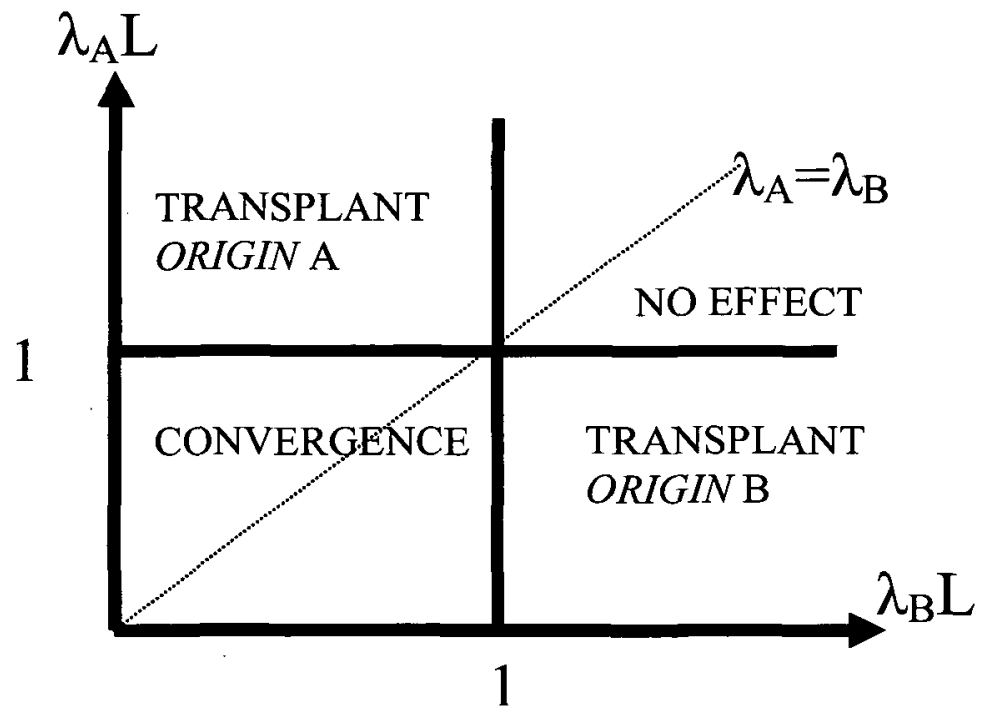

Figure 1. Possible equilibria of the game

and achieve the first-best legal solution. ${ }^{7}$ We should nevertheless be alert to the potential costs of this approach, which are discussed at the end of the section. A distinction is made between unification (one or more jurisdictions accept a new set of legal rules and practices that unifies law across countries without differentiability or flexibility) and harmonization (several jurisdictions accept an adjustment of existing real rules and practices by provisions in the law that reduce divergence although keeping differentiability and flexibility). In our view, unification and harmonization are in a sense the centralized counterparts of the competitive solutions that we have designated as transplant and convergence, respectively.

7. This setup makes sense because we have modeled a strictly noncooperative game. If countries may engage in side payments, which they often do, some of the conclusions concerning the need of third-party enforcement are weakened; countries are less likely to free ride if they can easily negotiate over and coordinate their laws. In a sense, this is the usual Coasean solution to externalities. If parties can negotiate at low transaction costs, an efficient solution is achievable without requiring intervention by third parties. However, in many cases, there are high transaction costs (agency costs within states, imperfect and asymmetric information concerning the effects of any given legal change, capture by pressure groups, lack of credibility in self-enforcing agreements, and so on). Hence, an efficient solution might require third-party enforcement as discussed in the text. 
Table 2. Pareto-Dominance Matrix

\begin{tabular}{ccc}
\hline & $\mathrm{W}$ & $\mathrm{N}$ \\
\hline $\mathrm{W}$ & Convention & Transplant \\
& $2-\left(\sigma_{\mathrm{A}}+\sigma_{\mathrm{B}}\right) L$ & $2-r_{\mathrm{A}} L$ \\
$\mathrm{~N}$ & Transplant & No effect \\
& $2-r_{\mathrm{B}} L$ & 0 \\
\hline
\end{tabular}

In order to investigate Pareto dominance, we start by looking at the total payoffs obtained in each possible outcome as shown by Table 2 .

Case 1. Suppose that $\sigma_{\mathrm{A}}+\sigma_{\mathrm{B}}>\min \left\{r_{\mathrm{A}}, r_{\mathrm{B}}\right\}$. Clearly a convention is less efficient than a unilateral transplant. There are, however, two possibilities. On the one hand, when we have $\left.\min \left\{r_{\mathrm{A}}, r_{\mathrm{B}}\right\} L\right\rangle 2,\langle\mathrm{~N}, \mathrm{~N}\rangle$ Pareto dominates (transplanting is simply too expensive); on the other hand, when we have $\min \left\{r_{A}, r_{B}\right\} L<2$, a unilateral transplant by the country with lower costs-the transplant — from the country with higher coststhe origin-is Pareto dominant.

Comparing the decentralized Nash equilibria and the Pareto-dominant solution, we can identify market or coordination failures that may justify some kind of corrective intervention:

1. $\min \left\{r_{\mathrm{A}}, r_{\mathrm{B}}\right\} L \geq 2$ (transplant is too costly). The no-effect competitive equilibrium is efficient, and no corrective intervention should be attempted.

2. $1<\min \left\{r_{\mathrm{A}}, r_{\mathrm{B}}\right\} L<2$. A unilateral transplant by the country with lower adjustment cost Pareto dominates, but the market fails because of the asymmetry on the distribution of costs of adjustment (that is, the public-good nature of transplants). The no-effect competitive equilibrium is inefficient, and there is the possibility of a corrective intervention of the type we have designated as unification.

3. $\min \left\{r_{\mathrm{A}}, r_{\mathrm{B}}\right\} L<1$ and $\max \left\{r_{\mathrm{A}}, r_{\mathrm{B}}\right\} L>1$. The transplant competitive equilibrium is efficient, and no corrective intervention is required.

4. $\max \left\{r_{\mathrm{A}}, r_{\mathrm{B}}\right\} L<1$. The convergence competitive equilibrium is inefficient since a unilateral transplant by the country with lower adjustment costs Pareto dominates. Some corrective intervention is useful to partially solve the inability of the market to arrive at complete convergence, a situation that we define as partial unification. However, this is a complex situation in which the convergence competitive equilibrium has already induced a waste of resources since the country with higher 




Figure 2. Possible equilibria of the game alongside the possible market failures

adjustment costs-the origin-should exert no effort to introduce changes in legal rules and practices.

In Figure 2, we represent the possible equilibria of the game alongside the possible market failures in relation to different values of the relevant parameters. Corrective interventions are more likely to be effective when the game is symmetric. Nevertheless, unification imposed by a third party can be a serious mistake when adjustment costs are very high or when transplant is already the competitive equilibrium. Finally, for low adjustment costs, we should have only partial unification, although there will be a waste of resources because of the expensive competitive convergence.

Case 2. Suppose $\sigma_{\mathrm{A}}+\sigma_{\mathrm{B}} \leq \min \left\{r_{\mathrm{A}}, r_{\mathrm{B}}\right\}$. Clearly a convention is more efficient than a unilateral transplant. There are two possibilities. On the one hand, when we have $\left(\sigma_{\mathrm{A}}+\sigma_{\mathrm{B}}\right) L>2,\langle\mathrm{~N}, \mathrm{~N}\rangle$ Pareto dominates $(\mathrm{a}$ convention is too expensive, and hence it is not efficient); on the other hand, when we have $\left(\sigma_{\mathrm{A}}+\sigma_{\mathrm{B}}\right) L<2$, it is $\langle\mathrm{W}, \mathrm{W}\rangle$ that Pareto dominates (convention is the most efficient outcome).

Comparing the decentralized Nash equilibria and the Pareto-dominant solution, we can again discuss market or coordination failures when 
a convention (which is never a Nash equilibrium) is more efficient than pure transplant:

1. $\left(\sigma_{\mathrm{A}}+\sigma_{\mathrm{B}}\right) L \geq 2$ (convention is too costly). The no-effect comperitive equilibrium is efficient, and a corrective intervention should be avoided.

2. $1<\left(\sigma_{\mathrm{A}}+\sigma_{\mathrm{B}}\right) L<2$ or $\left(\sigma_{\mathrm{A}}+\sigma_{\mathrm{B}}\right) L<1<\min \left\{r_{\mathrm{A}}, r_{\mathrm{B}}\right\} L$. The no-effect competitive equilibrium is inefficient since a convention should be achieved. There is the possibility of a corrective intervention, which we have designated as harmonization.

3. $\left(\sigma_{\mathrm{A}}+\sigma_{\mathrm{B}}\right) L<\min \left\{r_{\mathrm{A}}, r_{\mathrm{B}}\right\} L<1$ and $\max \left\{r_{\mathrm{A}}, r_{\mathrm{B}}\right\} L>1$. The transplant competitive equilibrium is inefficient since complete unification is achieved by the market, but not at the lowest cost.

4. $\left(\sigma_{\mathrm{A}}+\sigma_{\mathrm{B}}\right) L<\min \left\{r_{\mathrm{A}}, r_{\mathrm{B}}\right\} L<\max \left\{r_{\mathrm{A}}, r_{\mathrm{B}}\right\} L<1$. The convergence competitive equilibrium is inefficient since a convention is Pareto dominant. Some corrective intervention should be addressed to partially solve the inability of the market to arrive at complete convergence, a situation that we designate as partial harmonization. Notice, however, that there is no waste of resources since partial harmonization aims at solving the freeriding problem. In other words, both jurisdictions would be better off with a convention, but they are unable to fully coordinate in order to move there. No country is willing to unilaterally fully adjust its own set of legal rules and practices.

In considering different possible corrective interventions by a centralized authority, we should nevertheless take into account that the Pareto-dominant solution is not a Nash equilibrium. Thus, unification and harmonization force players to coordinate, but at the same time one must make sure that this coordination does indeed take place since the individual incentives point in the opposite direction (because of the freeriding problem). The inclusion of monitoring and enforcement costs obviously affects the efficiency condition for corrective interventions.

A second important issue is the possibility that unification and harmonization fail to recognize competitive efforts and advances in the approximation of legal rules and practices and hence result in duplication of costs and waste of resources. Another aspect is that countries may make mistakes, and therefore efforts toward unification or harmonization may result in laws that are more difficult to change over time.

These agency, monitoring, and enforcement costs, as well as duplication of adjustment costs with the possibility of mistakes, imply that the upper limit on adjustment costs to guarantee efficient unification or 
harmonization is strictly below 2 in the model. Therefore, it is possible that in some of the cases, harmonization or unification should not be pursued because there is a government failure (with high agency costs) substantially more important than a market or coordination failure.

\section{DISCUSSION}

We summarize the results of the model developed in the previous sections in Table 3. One possible interpretation for the three levels of adjustment costs (high, reasonable, and low) can be drawn from the concepts of facilitative and interventionist law, referred to in Section 1.

1. Interventionist law is expected to have relatively high adjustment costs since there is no obvious gain in terms of flow of tradable goods and services and since it is usually part of a long-entrenched system.

2. For facilitative law, where convergence has been driven by private willingness to adjust (law firms, private parties, or courts), public adjustment costs are not low. As we noted in Section 2, the costs of adjustment for private law could be relatively higher because the expected additional benefit is not so important (since public adjustment is an imperfect substitute for private adjustment of the law and legal practices) but not extremely high since these are areas not so long entrenched in the dynamics of the private intermediation. We suggest that the situation of facilitative law with substantial private intermediation can be understood as one of reasonable costs.

3. Facilitative law in areas with negligible private intermediation are plausibly those with low adjustment costs since the expected additional benefit from convergence by public authorities is more substantial.

An important issue in the policy implications is the symmetry of the game. We put forward two alternatives.

European Union and United States: Symmetric Game. The economic and military balance of power is loosely symmetric within these unions. Conventions by mutual agreement are expected to be less expensive than unilateral transplants given the economic and political complementarities.

Former Colonial Empires: Asymmetric Game. The balance of power clearly favors the origin. Unilateral transplant is more likely than con- 


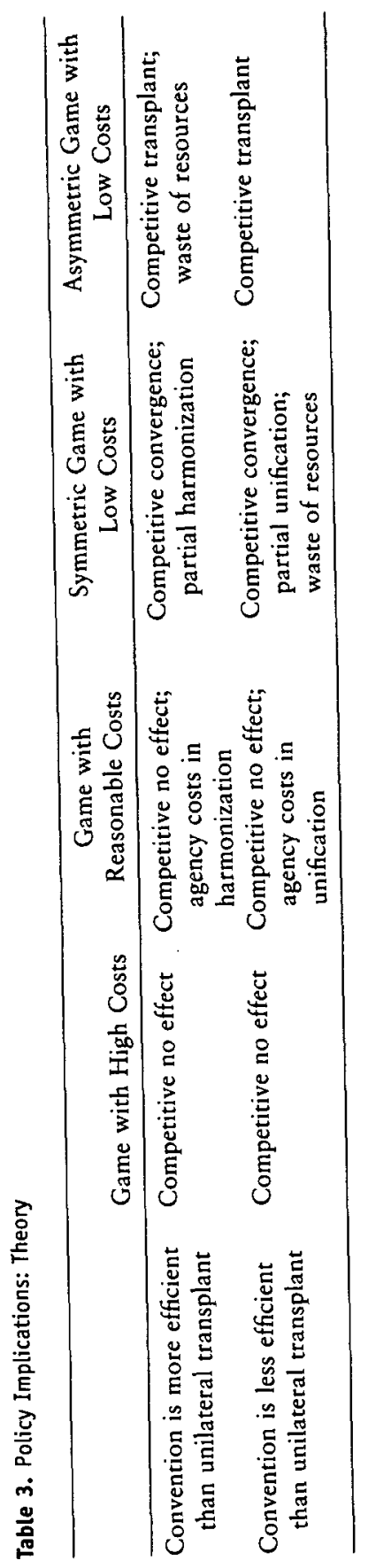


ventions, not least because of the complexity of the affected and entrenched interests in the former colonial power.

We can now present Table 4 as a suggestive summary of the implications of our model: Let us start by considering countries with less economic and military power (for example, former colonies). Typically, they are characterized by incipient private intermediation in the creation of legal rules and practices (not to be confused with corruption of public authorities). Our model suggests that they will transplant areas of the law that are fundamentally facilitative and less so areas that are interventionist (for corporate law and financial markets regulation, see La Porta et al. 1997, 1998; Coffee 1999; Choi 2002; Beck, Demirguc-Kunt, and Levine 2003a, 2003b; Pistor et al. 2003a, 2003b; and Rajan and Zingales 2003; for labor law, see Botero et al. 2004; for other aspects of the law, see Mahoney 2001). Unification of law raises serious questions given the possibility of agency costs (see Berkowitz, Pistor, and Richard [2003] on the costs that might undermine the economic success of transplants).

A corollary of these observations is that convergence of interventionist law is less likely, and more variance across jurisdictions should be observed. This seems to be supported by evidence that variations in areas such as tort law, family law, and administration of justice are more pronounced than in areas such as business law (for tort law, see Hartlief 2003; for more general legal institutions, see Chong and Zanforlin 2000; Djankov et al. 2002, 2003a, 2003b; La Porta et al. 2004; for a more general discussion, see Vranken 1997).

With respect to balanced federal jurisdictions (United States and European Union), our model suggests that we should observe areas of the law with weak convergence (interventionist law), areas of the law with some convergence driven by private intermediation and in which harmonization is highly questionable, and finally areas of the law with convergence driven by state (United States) or national (European Union) authorities in which partial harmonization might be useful to solve a market or coordination failure.

Concerning harmonization across federations, our analysis leads us to three important observations. First, our model gives support to incremental harmonization as a complement to convergence of legal systems and not total harmonization as a substitute for convergence, as it will most likely generate a duplication of costs (see Wagner [2002] on incremental harmonization).

Also consistent with our model is the observation that harmonization 





of private law (typically facilitative law with substantial private intermediation) is more controversial than harmonization of public law or regulation (many areas are facilitative law with less private intermediation) (see Caruso 1997; Legrand 1997; Joerges 2002; van Gerven 2004). In the European Union, major steps for harmonization have been taken primarily in facilitative law with little private intermediation (antitrust and administrative law, and regulation in general). Nevertheless, to some extent, such steps raise doubts concerning current European policy that aims at partial harmonization of interventionist law or facilitative law with substantial private intermediation by the imposition of minimum standards (see Farr 1996; Joerges 2002; also see Heine and Kerber 2002). Also in relation to international trade of goods and services, we suggest that current policy efforts might not be well advised since they seem to target areas with key private intermediation (for a comprehensive discussion of this problem, see Sykes 1999).

Finally, within a given area of the law, harmonization should target specific subareas in which interstate coordination is more difficult and private intermediation is weak. An immediate example to support this is tax law. Our model predicts that corporate tax regimes will be less different across countries than will income tax regimes for two reasons. The transboundary effect is certainly more important for corporate tax than for individual tax purposes. At the same time, adjustment costs are probably higher for income tax than for corporate tax law. Hence, while we expect some convergence of corporate tax law, the same would not apply to income tax law, and international developments largely support this prediction (in particular, see Ganghof and Eccleston 2004).

Our model gives rise to much caution in endorsing harmonization, because of agency costs (but see Trachtman 2000). Harmonization can be a corrective intervention, given a market or coordination failure, but we should be careful concerning the other side of the coin, a government failure. Monitoring and enforcement are more costly when the authority harmonizing is not able to easily measure and compare changes (for a discussion of this problem in the context of consumer protection, see Ogus 2002b). The European experience once more provides evidence: it has been easier to unify institutions and minimum legal standards or requirements than substantive and extensive legal rights and obligations. Maximal harmonization of consumer protection, a fairly modern legal intervention, seems to be easier to achieve than that of contract law or tort liability which are much more specific to each member state (see Wagner 2002; van Gerven 2004). The existence of general principles of 
law common to the member states in the European Union is still a matter of debate, and in fact they may contribute to misinterpretations concerning national rules of law (see Legrand 1996, 1999; Teubner 1998).

Monitoring and enforcement costs are also expected to be lower for formal changes than for real changes of legal practices. Although not as welfare enhancing, our model confirms that harmonization at a formal level is presumably more observable than at the practical level. Opposition to such symbolic changes of the law is usually not as strong as opposition to real changes in legal practices. Compliance with formal changes is achieved at a lower cost than compliance with real changes. Arguments against real changes usually include the need for understanding the role of national law, cultural identity, and national values as opposed to internalization of legal practice in which the international market ends up ruling the law and national identity is consequently lost (see Spar 1997; Mattei and Monti 2001).

Yet another problem concerning monitoring and enforcement costs of harmonization is the heterogeneity of the federation, not only in terms of the obvious consequences for a more difficult bargaining process but also because it generates a more diverse recruitment of judges and advocates general and consequently a more heterogeneous European Court of Justice with respect to the production and the role of European lawall of this in clear contrast to the United States (see Douglas-Scott [2002, chap. 5] on the heterogeneity of the members of the European Court of Justice).

Duplication of costs and mistakes in harmonization should not be neglected in evaluating harmonization or unification. There is evidence that in certain areas of the law, the existing failure of regulatory reforms may just reflect the substantial importance of those effects (see Hertig [2000] on financial markets).

We have assumed implicitly that there are no ex ante bargaining failures once countries enter a political and legal process that will achieve harmonization of certain legal regimes and practices (we have acknowledged ex post failures by which countries agree with the new regime but defect after that). Our assumption is based on the idea that the role of a third party is precisely to ensure bargaining success, which makes it quite different from convergence, in which a third party does not intervene. Nevertheless, as American and European legal history shows, the political process underlying legal harmonization is subject to successes and failures. A third party (even in the role of federal government or 
an international organization) is no guarantee of bargaining accomplishment.

\section{FINAL REMARKS}

Previous literature has recognized the importance of competition in the supply of legal rules as a major determinant of the evolution of law. The pressure generated by migration to more favorable jurisdictions and network externalities has been used to explain convergence and the socalled transplant effect. In this paper, we argue that countries hesitate to modify their laws toward another country's regime because they hope to free ride on the efforts of the latter to modify their laws toward convergence. Unification (by transplant) and harmonization (by convention) of legal rules emerge as obvious corrective interventions to a coordination failure, thus solving the free-riding problem. However, unification and harmonization could also be serious policy mistakes either because convergence is absent, given very high costs of adjustment or because of agency costs. The nature of these costs may well justify some harmonization in some areas of law, but it may also effectively protect other areas of law from inefficient harmonization. Different legal realities may coexist because of different preferences as well as technological constraints (in this context, institutional design and rent seeking). Unification and harmonization should tackle the latter but not the former.

It may be helpful to conclude with some thoughts on how our results might be extended to a multicountry framework. Complexities exist in a multicountry framework that are absent in the two-country model. For example, the lower the cost of going to a particular regime as more countries use that regime, the quicker a given country can make its regime the standard in sequential interaction with various countries over time. ${ }^{8}$ Nevertheless, legal convergence could be more difficult in the early stages because there are more alternatives available; that is, the multitude of countries could increase the transaction costs of switching significantly above those arising in a two-country model.

8. For example, Ogus (2002a) treats legal culture as a network, reducing the costs of communication and adherence. 


\section{REFERENCES}

Bebchuk, Lucian Arye. 1992. Federalism and the Corporation: The Desirable Limits on State Competition in Corporate Law. Harvard Law Review 105: 1437-1510.

Bebchuk, Lucian Arye, and Alma Cohen. 2003. Firms' Decision Where to Incorporate. Journal of Law and Economics 46:383-425.

Bebchuk, Lucian Arye, and Assaf Hamdani. 2002. Vigorous Race or Leisurely Walk: Reconsidering Competition over Corporate Charters. Yale Law Journal 112:553-615.

Beck, Thorsten, Asli Demirguc-Kunt, and Ross Levine. 2003a. Law and Finance: Why Does Legal Origin Matter? Journal of Comparative Economics 31: $653-75$.

. 2003b. Law, Endowment, and Finance. Journal of Financial Economics 70:137-81.

Berkowitz, Daniel, Katharina Pistor, and Jean-Francois Richard. 2003. Economic Development, Legality, and the Transplant Effect. European Economic Review 47:165-95.

Botero, Juan C., Simeon Djankov, Rafael La Porta, Florencio Lopez-de-Silanes, and Andrei Shleifer. 2004. The Regulation of Labor. Quarterly Journal of Economics 119:1339-82.

Caruso, Daniela. 1997. The Missing View of the Cathedral: The Private Law Paradigm of European Legal Integration. European Law Review 3:3-32.

Choi, Stephen J. 2002. Law, Finance, and Path Dependence: Developing Strong Securities Markets. Texas Law Review 80:1657-1727.

Chong, Alberto, and Luisa Zanforlin. 2000. Law Tradition and Institutional Quality: Some Empirical Evidence. Journal of International Development 12: 1057-68.

Coffee, John C., Jr. 1999. The Future as History: Prospects for Global Convergence in Corporate Governance and Its Implications. Northwestern University Law Review 93:641-707.

Djankov, Simeon, Edward L. Glaeser, Rafael La Porta, Florencio Lopez-deSilanes, and Andrei Shleifer. 2003a. The New Comparative Economics. Journal of Comparative Economics 31:595-619.

Djankov, Simeon, Rafael La Porta, Florencio Lopez-de-Silanes, and Andrei Shleifer. 2002. Regulation of Entry. Quarterly Journal of Economics 117:1-37.

- 2003b. Courts. Quarterly Journal of Economics 118:453-517.

Douglas-Scott, Sionaidh. 2002. Constitutional Law of the European Union. London: Pearson Longman.

Easterbrook, Frank H. 1994. Federalism and European Business Law. International Review of Law and Economics 14:125-32.

Esty, Daniel C., and Damien Geradin. 2000. Regulatory Co-opetition. Journal of International Economic Law 3:235-55. 
—_, eds. 2001. Regulatory Competition and Economic Integration: Comparative Perspectives. Oxford: Oxford University Press.

Farr, Sebastian. 1996. Harmonisation of Technical Standards in the EC. $2 \mathrm{~d}$ ed, Chichester: Wiley.

Faure, Michael G. 2003. How Law and Economics May Contribute to the Harmonization of Tort Law in Europe. Pp. 31-82 in Grundstrukturem des Europaeischen Deliktsrechts, edited by Reinhard Zimmerman. Baden Baden: Nomos Verlagsgesellschaft.

Ganghof, Steffen, and Richard Eccleston. 2004. Globalisation and the Dilemmas of Income Taxation in Australia. Australian Journal of Political Science 39: 519-34.

Hadfield, Gillian K. 2000. The Price of Law: How the Market for Lawyers Distorts the Justice System. Michigan Law Review 98:953-1006.

Hartlief, Ton. 2003. Harmonization of European Tort Law. Some Critical Remarks. Pp. 225-36 in Towards a European Ius Commune in Legal Education and Research, edited by Michael Faure, Jan Smits, and Hildegard Schneider. Antwerp: Intersentia.

Hay, Bruce L. 1992. Conflicts of Law and State Competition in the Product Liability System. Georgetown Law Journal 80:617-52.

Heine, Klaus, and Wolfgang Kerber. 2002. European Corporate Laws, Regulatory Competition and Path Dependence. European Journal of Law and Economics 13:47-71.

Hertig, Gerard. 2000. Regulatory Competition for EU Financial Services. Journal of International Economic Law 3:349-75.

Hesselink, Martijn W. 2001. The New European Legal Culture. Deventer: Kluwer.

Joerges, Christian. 2002. On the Legitimacy of Europeanising Europe's Private Law. Global Jurist Topics 2(2), art. 1, pp. 1-8. http://www.bepress.com/gj/ topics/vol2/iss2/art1.

Kahan, Marcel, and Ehud Kamar. 2002. The Myth of State Competition in Corporate Law. Stanford Law Review 55:679-749.

La Porta, Rafael, Florencio López-de-Silanes, Cristian Pop Eleches, and Andrei Shleifer. 2004. Judicial Checks and Balances. Journal of Political Economy 112:445-70.

La Porta, Rafael, Florencio Lopez-de-Silanes, Andrei Shleifer, and Robert W. Vishny. 1997. Legal Determinants of External Finance. Journal of Finance 52:1131-50.

- 1998. Law and Finance. Journal of Political Economy 106:1113-55.

Legrand, Pierre. 1996. European Legal Systems Are Not Converging. International and Comparative Law Quarterly 45:52-81.

- 1997. Against a European Civil Code. Modern Law Review 60:44-63.

-1999. Fragments on Law-as-Culture. Deventer: W. E. J. Tjeen Willink. 
Levmore, Saul. 1983. Interstate Exploitation and Judicial Intervention. Virginia Law Review 69:563-631.

Linarelli, John. 2003. The Economics of Uniform Laws and Uniform Lawmaking. Wayne Law Review 48:1387-1447.

Mahoney, Paul G. 2001. The Common Law and Economic Growth: Hayek Might Be Right. Journal of Legal Studies 30:503-25.

Mattei, Ugo. 1994. Efficiency in Legal Transplants: An Essay in Comparative Law and Economics. International Review of Law and Economics 14:3-21.

- 1998. The Issue of European Civil Codifications and Legal Scholarship: Biases, Strategies, and Developments. Hastings International and Comparative Law Review 21:883-1000.

Mattei, Ugo, and Alberto Monti. 2001. Comparative Law and Economics: Borrowing and Resistance. Global Jurist Frontiers 1(2), art. 5, pp. 1-26. http:/l www.bepress.com/gj/frontiers/vol1/iss2/art5.

Matrei, Ugo, and Francesco Pulitini. 1991. A Competitive Model of Legal Rules. Pp. 207-19 in The Competitive State: Villa Colombella Papers on Competitive Politics, edited by Albert Breton, Gianluigi Galeotti, Pierre Salmon, and Ronald Wintrobe. Dordrecht: Kluwer.

Ogus, Anthony. 1999. Competition between National Legal Systems: A Contribution of Economic Analysis to Comparative Law. International and Comparative Law Quarterly 48:405-18.

- 2002a. The Economic Basis of Legal Culture: Networks and Monopolization. Oxford Journal of Legal Studies 22:419-34.

- 2002b. Enforcing Consumer Protection Regulation in a European Context. Pp. 263-78 in Konsequenzen wirtschaftsrechtlicher Normen: Festschrift für Claus Ott zum 65. Geburtstag, edited by Hans-Bernd Schäfer and Hans-Jurgen Lwowski. Wiesbaden: Gabler Verlag.

Pistor, Katharina, Yoram Keinan, Jan I. Kleinheisterkamp, and Mark D. West. 2003a. The Evolution of Corporate Law: A Cross-Country Comparison. University of Pennsylvania Journal of International Economic Law 23:791-871.

. 2003b. Innovation in Corporate Law. Journal of Comparative Economics 31:676-94.

Posner, Richard A. 1987. The Constitution as an Economic Document. George Washington Law Review 56:4-38.

Rajan, Raghuram G., and Luigi Zingales. 2003. The Great Reversals: The Politics of Financial Development in the 20th Century. Journal of Financial Economics 69:5-50.

Revesz, Richard L. 1992. Rehabilitating Interstate Competition: Rethinking the "Race-to-the-Bottom" Rationale for Federal Environmental Regulation. New York University Law Review 67:1210-54.

- 1996. Federalism and Interstate Environmental Externalities. University of Pennsylvania Law Review 144:2341-2416.

- 2000. Federalism and Regulation: Extrapolating from the Analysis of 
Environmental Regulation in the United States. Journal of International Economic Law 3:219-33.

Ribstein, Larry E. 1993. Choosing Law by Contract. Journal of Corporation Law 18:245-300.

- 2002. Market vs. Regulatory Responses to Corporate Fraud: A Critique of the Sarbanes-Oxley Act of 2002. Journal of Corporation Law 28:1-67.

- 2004. Lawyers as Lawmakers: A Theory of Lawyer Licensing. Missouri Law Review: 69:299-366.

Ribstein, Larry E., and Bruce H. Kobayashi. 1996a. An Economic Analysis of Uniform State Laws. Journal of Legal Studies 25:131-200.

1996b. Evolution and Spontaneous Uniformity: Evidence from the Evolution of the Limited Liability Company. Economic Inquiry 34:464-83.

Roe, Mark J. 2003. Delaware's Competition. Harvard Law Review 117:590-646.

Romano, Roberta. 1987. The Political Economy of Takeover Statutes. Virginia Law Review 73:111-99.

- 2002. The Advantage of Competitive Federalism for Securities Regulation. Washington, D.C.: American Enterprise Institute for Public Policy Research.

- 2005. Is Regulatory Competition a Problem or Irrelevant for Corporate Governance? Oxford Review of Economic Policy 21:212-31.

Smits, Jan. 1998. A European Private Law as a Mixed Legal System. Maastricht Journal of European and Comparative Law 5:328-40.

Spar, Debora L. 1997. Lawyers Abroad: The Internalization of Legal Practice. California Management Review 39(3):8-28.

Sykes, Alan O. 1999. The Limited Role of Regulatory Harmonization in International Goods and Services Markets. Journal of International Economic Law 2:49-70.

- 2000. Regulatory Competition or Regulatory Harmonization? A Silly Question? Journal of International Economic Law 3:257-64.

Teubner, Gunther. 1998. Legal Irritants: Good Faith in British Law or How Unifying Law Ends up in New Divergences. Modern Law Review 61:11-32.

Trachtman, Joel P. 2000. Regulatory Competition and Regulatory Jurisdiction. Journal of International Economic Law 3:331-48.

van Gerven, Walter. 2004. Harmonization of Private Law: Do We Need It? Common Market Law Review 41:505-32.

Vranken, Martin. 1997. Fundamentals of European Civil Law and Impact of the European Community. Sydney: Federation Press.

Wagner, Gerhard. 2002. The Economics of Harmonization: The Case of Contract Law. Common Market Law Review 39:995-1023.

Watson, Alan. 1985. The Evolution of Law. Oxford: Blackwell.

Zimmermann, Reinhard. 2001. Roman Law, Contemporary Law, European Law: The Civilian Tradition Today. Oxford: Oxford University Press.

Zweigert, Konrad, and Hein Kötz. 1998. An Introduction to Comparative Law. $3 d$ ed. Oxford: Oxford University Press. 
